\section{Preharvest Application of Methyl Jasmonate to 'Fuji' Apples Enhances Red Coloration and Affects Fruit Size, Splitting, and Bitter Pit Incidence}

\author{
David R. Rudell ${ }^{1}$ and John K. Fellman ${ }^{2}$ \\ Department of Horticulture and Landscape Architecture, Washington State \\ University, Pullman, WA 99146-6414 \\ James P. Mattheis ${ }^{3}$ \\ U.S. Department of Agriculture, Agricultural Research Service, Tree FruitResearch \\ Laboratory, 1104 North Western Avenue, Wenatchee, WA 98801-1230
}

Additional index words. Malus sylvestris var. domestica, color, anthocyanin, bitter pit, maturation

\begin{abstract}
Repeated preharvest applications of methyl jasmonate (MJ) to 'Fuji' apple [Malus sylvestris var. domestica (Borkh.) Mansf.] fruit were evaluated for impacts on peel color, size, fruit finish, and maturation. MJ treatments at 2 week intervals began 48 days after full bloom (DAFB) (early season) or 119 DAFB (late season) and fruit were harvested 172 DAFB. MJ treatment stimulated significant increases in peel red color following the initial application and thereafter. Early season $\mathrm{MJ}$ treatment reduced fruit diameter and length to diameter ratio but slowed softening and starch hydrolysis. Fruit receiving late season MJ treatments had increased incidence of bitter pit and splitting, shorter green life, and slower softening. Results suggest preharvest application of $\mathrm{MJ}$ impacts apple color development and other aspects of fruit quality. Chemical name used: methyl 3-oxo2-(2-pentenyl)cyclopentane-1-acetate (methyl jasmonate).
\end{abstract}

Red peel color is an important commercial grading criterion and contributes to the marketability of many apple [Malus sylvestris var. domestica (Borkh.) Mansf.] cultivars. Anthocyanins, carotenoids, and xanthophylls are the primary peel components that contribute to apple color (Sun and Francis, 1967; Workman, 1963). These pigments along with other flavonoids also function in photoprotection (Merzlyak and Chivkunova, 2000).

Methyl jasmonate (MJ) enhances anthocyanin production in a wide variety of plant materials including seedlings of soybean (Glycine max Merr.) (Franceschi and Grimes, 1991) and Arabidopsis thaliana (L.) (Feys et al., 1994), tulip bulbs (Tulipa gesneriana L.) (Saniewski et al., 1998a), and peach shoots (Prunus persica Batsch.) (Saniewski et al., 1998b). MJ also enhances anthocyanin synthesis in 'Tsugaru' apple fruit peel disks (Kondo et al., 2001) and whole 'Fuji' apple fruit peel under laboratory conditions while also stimulating production of quercetin glycosides and other phenolic compounds (Rudell et al., 2002). MJ stimulates ß-carotene biosynthesis in 'Golden Delicious' apple peel in the dark (Perez et al., 1993) and in 'Fuji' peel in concert with UV/visible light along with chlorophyll b (Rudell et al., 2002). Increased red color development in apple fruit coincides with heightened jasmonic acid (JA) levels early in fruit development as well as near

Received for publication 13 Aug. 2004. Accepted for publication 28 June 2005.

${ }^{1}$ Graduate research assistant.

${ }^{2}$ Professor.

${ }^{3}$ Research plant physiologist and corresponding author; e-mail mattheis@tfrl.ars.usda.gov. the onset of ripening (Fan et al., 1998). These results suggest jasmonates may be involved in promoting apple fruit anthocyanin formation in situ.

Our objective was to determine if preharvest applications of MJ to 'Fuji' apple fruit alters color development and other aspects of fruit quality.

\section{Materials and Methods}

Experiments were carried out using BC2/M9 'Fuji' apple trees in the sixth leaf. Trees were hand-thinned to one fruit per cluster and fruit with the greatest sunlight exposure were selected and tagged around the petiole at $39 \mathrm{~d}$ after full bloom (DAFB). Thirty evenly distributed fruit were selected on each tree.

Treatments were applied to fruit at 2-week intervals using hand-pump-actuated spray ments included $0,1.12,2.24$, and $4.48 \mathrm{~g} \cdot \mathrm{L}^{-1}$ methyl jasmonate (Aldrich, Milwaukee, Wis.) in an aqueous emulsion containing $0.077 \%$ (v/v) Triton X-100 (octoxynol, Aldrich). The first group of treatments was applied starting 48 DAFB (early season; five trees per treatment) and the second group 119 DAFB (late season; five trees per treatment).

Peel color of the sun-exposed side of each fruit was analyzed weekly using a colorimeter (CR-200; Minolta Corp., Osaka, Japan). Measurements were obtained using the CIE L* (light to dark) $\mathrm{a}^{*}$ (green to red) $\mathrm{b}^{*}$ (blue to yellow) color space, then $a^{*} b^{*}$ values were converted to hue angle ( $\mathrm{h}^{\circ}, \tan ^{-1} \mathrm{~b} / \mathrm{a}$; McGuire, 1992). Air temperature was recorded every $0.5 \mathrm{~h}$ at a bottles. Each fruit was sprayed to drip. Treat- weather station located within the orchard.

Fruit circumference was measured 123 DAFB and following harvest (172 DAFB) using a tape measure around the fruit equator and length was measured only at harvest using a digital caliper (Max-Cal; Fowler Co., Newton, Mass). Following harvest, fruit length, weight, stem end and calyx cracking, bitter-pit severity, and treatment-related peel damage were evaluated. Cracking severity was scored as $0=$ no cracking; $1=$ crack on the stem end or the calyx end; 2 = cracking on both ends. Bitter pit severity was rated $0=$ none; $1=$ present on $1 \%$ to $25 \%$ of the fruit surface; $2=26 \%$ to $50 \%$ of surface; $3=51 \%$ to $75 \%$ of surface; $4=76 \%$ to $100 \%$ of surface. Any treatment related peel marking was noted.

Whole-fruit ethylene evolution and respiration, flesh firmness, and starch content were evaluated following harvest. Ethylene evolution and whole fruit respiration were monitored daily as described (Rudell et al., 2002). Flesh firmness was measured using an EPT-1 recording penetrometer (Lake City Technical Products, Inc., Kelowna, BC, Canada), set on MagnessTaylor mode and using an 11-mm tip. Starch content was visually scored from 1 to $6(1=$ $>95 \%$ starch $; 6=<3 \%$ starch) following staining an equatorial cross-section of each fruit with a $0.5 \% \mathrm{I}-\mathrm{KI}$ solution.

Peel and cortical tissue were sampled from four apples and then compiled individually (one replication) for mineral analysis (three replications per block; $n=15$ ). Following sampling, tissue was frozen at $-20^{\circ} \mathrm{C}$, lyophilized, and stored at $-20^{\circ} \mathrm{C}$ until preparation and analysis. Prior to analysis, $1 \mathrm{~g}$ of each sample was ground using a Wiley mill, ashed overnight at $475^{\circ} \mathrm{C}$ and, upon cooling, dissolved in $5 \mathrm{~mL}$ of $5.56 \mathrm{~N}$ $\mathrm{HCl}$ for $10 \mathrm{~min}$. Each sample was then diluted to $25 \mathrm{~mL}$ and analyzed for $\mathrm{Ca}^{2+}, \mathrm{Mg}^{2+}$, and $\mathrm{K}^{+}$ using inductively coupled plasma spectroscopy (ICP)(Optima 4300 DV; Perkin-Elmer, Shelton, Conn.).

Experimental design and statistical analyses. Experiments were conducted using a randomized complete block design. Regression analyses were performed on continuous and categorical data using the general linear model or logistic model, respectively (SAS V 8.0, SAS Institute, Cary, N.C.). No significant differences were found between early and late season control fruit in any of the tests reported, therefore, only the early season controls were used for statistical analyses.

\section{Results}

Peel red color of both early and late season fruit significantly increased $\left(\right.$ decreased $\left.h^{\circ}\right)$ with MJ treatment concentration within a week following the initial treatments (Fig. 1). The differences in red coloration were also detectable visually. Although MJ treatment stimulated increased peel red color, it did not appear to fully overcome other factors impacting red color development such as orchard air temperature. Changes in peel red color that occurred regardless of MJ treatment accompanied increases and decreases in daily orchard temperature (temp. data not shown). Incidence of sunburn was 


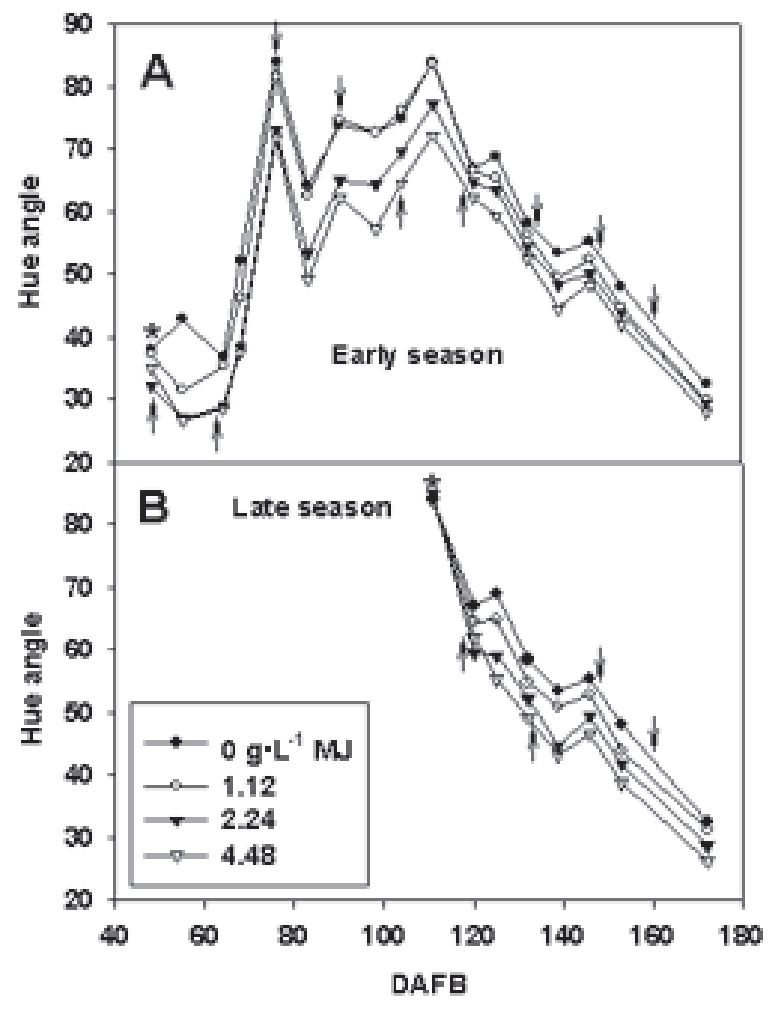

was negatively affected by early season MJ treatments. The average fruit weight also decreased with MJ treatment concentration. Late season MJ treatments did not alter fruit diameter, weight, or length/diameter ratio.

Late season MJ treatments stimulated the development of bitter-pit, and stem-bowl and calyx-end cracking(Table 1). Bitter-pit severity, but not cracking, increased with $\mathrm{MJ}$ concentration to a lesser degree in fruit receiving early season treatments. Bitter-pit symptoms were noticeable on late season fruit treated with 2.24 or $4.48 \mathrm{~g} \cdot \mathrm{L}^{-1} \mathrm{MJ}$ about 2 weeks following the initial application. Similar symptoms on fruit treated with $1.12 \mathrm{~g} \cdot \mathrm{L}^{-1} \mathrm{MJ}$ (late season) and early season treatments at higher doses were noticeable near harvest. Postharvest fruit mineral analysis revealed no significant relationships between peel or flesh $\mathrm{Ca}^{2+}, \mathrm{Mg}^{2+}$, and $\mathrm{K}^{+}$ concentrations and $\mathrm{MJ}$ treatment (data not presented).

Fruit firmness increased with

Fig. 1. Hue angle $\left({ }^{\circ} h\right)$ of 'Fuji' apple fruit sprayed bimonthly with methyl jasmonate (MJ) starting $48 \mathrm{~d}$ after full bloom (DAFB) (A) or 119 DAFB (B). Arrows designate treatment dates. Asterisks designate sampling dates where no significant difference was found.

not affected by MJ (data not presented). Peel russeting was present on all treatments including the control, but not on non-sprayed fruit, suggesting the adjuvant may have caused this injury (data not presented).

Early season $\mathrm{MJ}$ treatments reduced fruit size (Table 1). At 123 DAFB and at harvest (172 DAFB), fruit diameter decreased with increased MJ concentration. Decreased fruit size was also reflected by decreased length to diameter ratio, indicating that fruit elongation or type
MJ treatment concentration regardless of when treatments were applied although this was more pronounced in fruit treated in the early season (Table 1). Starch hydrolysis decreased slightly with MJ concentration in early season treatments. Fruit treated during the late season at 4.48 $\mathrm{g} \cdot \mathrm{L}^{-1} \mathrm{MJ}$ had higher respiration rate and ethylene evolution at harvest compared to controls (Fig. 2). Postharvest respiration was altered by both MJ timing protocols and ethylene production was highest throughout the postharvest evaluation period for fruit to which $\mathrm{MJ}$ was applied late in the season.

\section{Discussion}

Field application of MJ to 'Fuji' apple fruit can enhance red color development. This response is visually and instrumentally detectable within days of the initial application, and repeated application does not stimulate a further increase. In this study, peel coloration may also have been associated with air temperature and, while significant differences were maintained, general trends of red color gain and loss exhibited by all of the fruit were not affected by MJ. For some apple cultivars, peel red coloration can be enhanced in response to cool temperatures (Uota, 1952) and can decrease with warmer temperatures (Creasy, 1968). Positive effects of cooler temperatures on red coloration have also been demonstrated in laboratory experiments using detatched fruit (Reay, 1999).

Jasmonate signaling is associated with wound responses (Creelman and Mullet, 1997). Anthocyanins may contribute to photoprotection in some apple cultivars (Merzlyak and Chivkunova, 2000), therefore enhancement of anthocyanin synthesis by MJ may contribute to adaptation to light stress. However, in the current study, MJ application had no effect on sunburn, a superficial peel disorder in apples resulting from high light and heat conditions (Ritenour etal., 2001). This indicates thatjasmonates have little role in light stimulated wound response in apple peel or that $\mathrm{MJ}$ mediation of these signals alone does not prevent sunburn symptom development.

Application of MJ significantly influenced fruit diameter, length to diameter ratio, stem and calyx-end cracking, and bitter pit incidence. The fact that fruit diameter and length to diameter ratio were affected by $\mathrm{MJ}$ treatment only for fruit treated during the early season suggests MJ can impact early season cell growth and/or division, but not late season fruit growth. Cell division ceases between 3 to 12 weeks after full bloom, depending on the cultivar and the length of this period is greatly affected by seasonal climatic conditions (Al-Hinai and Roper, 2004). Initiation of the early season treatments may have been close to the developmental period when cell division ceased. Inhibition of cell expansion at this early stage may explain the differences in fruit size and shape. Apple fruit size and elongation can be enhanced by

Table 1. 'Fuji' apple fruit characteristics following treatments with methyl jasmonate (MJ). Evaluations were performed at harvest or as indicated. MJ treatments were applied bimonthly starting 48 (early season) or $119 \mathrm{~d}$ after full bloom (late season).

\begin{tabular}{|c|c|c|c|c|c|c|}
\hline & \multirow{2}{*}{$\begin{array}{l}\text { Application } \\
\text { timing }\end{array}$} & \multicolumn{4}{|c|}{ Treatment } & \multirow{2}{*}{$\begin{array}{c}\text { Linear } \\
\text { fit }\end{array}$} \\
\hline & & $0 \mathrm{~g} \cdot \mathrm{L}^{-1} \mathrm{MJ}$ & $1.12 \mathrm{~g} \cdot \mathrm{L}^{-1} \mathrm{MJ}$ & $2.24 \mathrm{~g} \cdot \mathrm{L}^{-1} \mathrm{MJ}$ & $4.48 \mathrm{~g} \cdot \mathrm{L}^{-1} \mathrm{MJ}$ & \\
\hline \multirow[t]{2}{*}{ Final $^{\circ} \mathrm{h}(\mathrm{n}=150)$} & Early & 32.4 & 29.9 & 29.4 & 28.0 & $*$ \\
\hline & Late & --- & 31.1 & 28.6 & 26.2 & $*$ \\
\hline Diameter $(\mathrm{mm})(123$ DAFB $)(\mathrm{n}=90)$ & Early & 75.2 & 69.3 & 65.4 & 61.0 & $*$ \\
\hline \multirow{2}{*}{ Diameter $(\mathrm{mm})($ at harvest $)(\mathrm{n}=90)$} & Early & 85.7 & 79.8 & 76.7 & 71.4 & $*$ \\
\hline & Late & --- & 84.8 & 86.9 & 85.6 & NS \\
\hline \multirow[t]{2}{*}{ Length to diameter ratio $(n=90)$} & Early & 0.873 & 0.823 & 0.812 & 0.800 & $*$ \\
\hline & Late & --- & 0.853 & 0.850 & 0.851 & NS \\
\hline \multirow{2}{*}{ Average fruit weight $(\mathrm{g})(\mathrm{n}=8)^{\mathrm{z}}$} & Early & 272.6 & 219.5 & 196.1 & 158.8 & $*$ \\
\hline & Late & --- & 259.2 & 275.1 & 252.9 & NS \\
\hline \multirow{2}{*}{ Bitter pit severity $(0-4)(n=90)$} & Early & 0.048 & 0.16 & 0.17 & 0.22 & $*$ \\
\hline & Late & --- & 1.0 & 1.5 & 2.1 & $*$ \\
\hline \multirow{2}{*}{ Cracking incidence $(0-2)(n=90)$} & Early & 0.024 & 0.034 & 0.036 & 0.046 & NS \\
\hline & Late & --- & 0.070 & 0.29 & 0.29 & $*$ \\
\hline \multirow{2}{*}{ Fruit firmness (lb) $(n=48)$} & Early & 11.4 & 12.2 & 12.7 & 13.6 & $*$ \\
\hline & Late & --- & 11.7 & 11.8 & 12.2 & $*$ \\
\hline \multirow[t]{2}{*}{ Starch score $(1-6)(n=48)$} & Early & 4.8 & 3.5 & 3.3 & 3.5 & $*$ \\
\hline & Late & --- & 4.5 & 4.3 & 4.3 & NS \\
\hline
\end{tabular}

${ }^{\mathrm{z}}$ Each replication is a composite of 15 individual fruit.

NS, ${ }^{*}$ Nonsignificant or significant fit at $P \leq 0.05, \mathrm{n}$ is given in left hand column. 


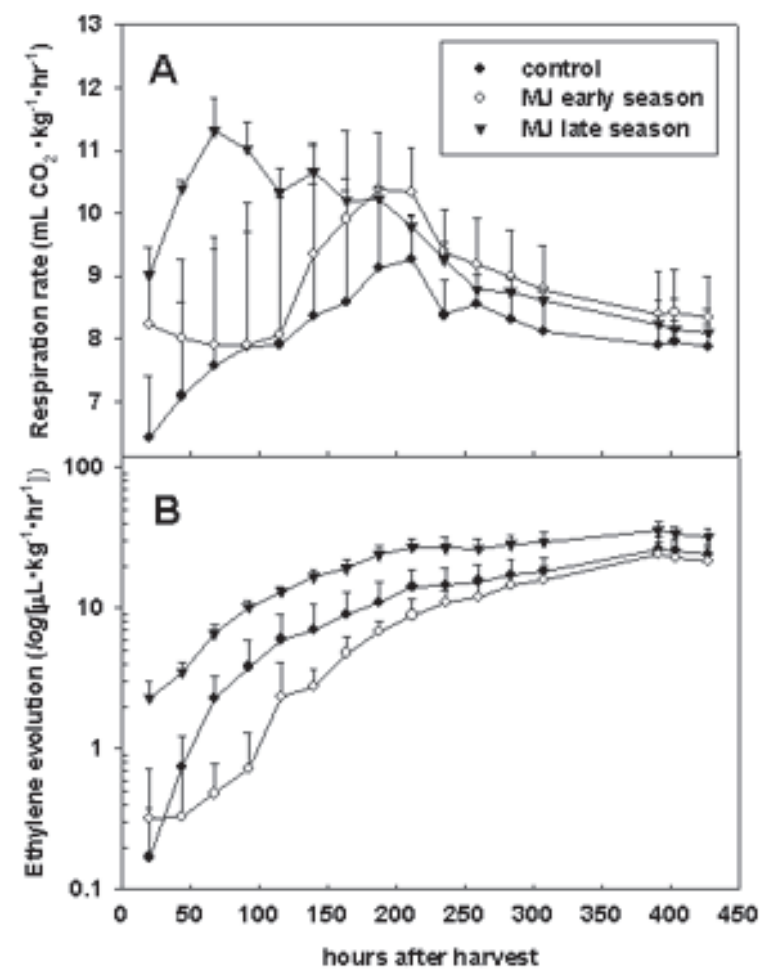

Fig. 2. Respiration rate (A) and ethylene evolution plotted on a logarithmic scale (B) of 'Fuji' apple fruit measured at harvest. Fruit were sprayed with an emulsion containing 0 (control) or $4.48 \mathrm{~g} \cdot \mathrm{L}^{-1} \mathrm{MJ}$ starting at $48 \mathrm{~d}$ after full bloom (DAFB) (early season) or 119DAFB(late season). Errorbars represent $\mathrm{SE}(\mathrm{n}=3$ pooled samples of 5 fruit each).

treatment with certain gibberellic acids (GA) (Bukovac and Nakagawa, 1968; Looney, 1979) and are reduced by paclobutrazol, a GAsynthesis inhibitor (Privé et al., 1989). Jasmonates purportedly inhibit GA-stimulated cell division in grape (Vitis vinifera L.) fruit tissue (Kondo and Fukuda, 2001) and cell elongation of corn (Zea mays L.) coleoptiles (Irving et al., 1999).

Development of bitter-pit (DeLong, 1936), stem and calyx-end cracking, and splitting (Perring, 1984) have been attributed to calcium deficiency or an imbalance of calcium with magnesium or potassium (Chiu and Bould, 1977). Mineral analysis of fruit in this study did not reveal any impact of MJ treatments on fruitmineral content. Saure (1996) hypothesized that calcium may play a secondary role in bitter pit incidence to other factors such as high lateseason GAlevels. Paclobutrazol (Greene, 1986) and GA antagonists like ABA and ethylene that increase in the flesh as apples mature may act to curtail bitter-pit development, explaining why early harvested fruit are more susceptible to postharvest development of this disorder (Saure, 1996).As with fruit growth, interactions between jasmonates and GA may play a role in bitter-pit formation. Differential severity of these symptoms resulting from treatment timing may only reflect the varying propensity for slow growth and bitter pit formation early or late, respectively, in the season. There is also the possibility that, while these symptoms were indistinguishable from severe bitter pit, they actually resulted from different causes.

Based on respiration rate and ethylene evolu- tion, fruit treated with MJ during the late season were more mature at harvest, followed by controls and then by fruit treated during the early season. These results agree with Fan et al. (1997) where MJ treatment stimulated climacteric levels of ethylene production in mature, albeit preclimacteric, apples. However, firmness and starch levels increased with MJ treatment in fruit treated during the early or late season indicating MJ differentially impacted some other maturation-related processes. Higherfirmness of fruit treated during the early season may be due to reduced fruit size, however, higher firmness of fruit treated during the late season was not due to reduced fruit size.

In conclusion, repeated MJ treatment significantly increased peel red color of 'Fuji' apple fruit. The increase in red color was reflected both visually and by a significant linear decrease in $\mathrm{h}^{\circ}$ with increasing MJ concentration. Although our results indicate fewer MJ applications within the month before harvest of 'Fuji' apples could be sufficient, further investigations are needed to address the timing and effects of MJ treatment regimes and the longevity of effects on fruit color and whole tree physiology. Furthermore, the deleterious MJ effects resulting in reduced fruit size, bitter pit and cracking indicate a need to more fully understand the role of jasmonates in apple fruit development.

\section{Literature Cited}

Al-Hinai,Y.K. and T.R. Roper. 2004. Rootstock effects on growth, cell number, and cell size of 'Gala' apples. J. Amer. Soc. Hort. Sci. 129:37-41.

Bukovac, M.J. and S. Nakagawa. 1968. Gibberellin-induced asymmetric growth of apple fruits. HortScience 3:172-174.

Chiu, T.F. and C. Bould. 1977. Sand-culture studies on the calcium nutrition of young apple trees with particular reference to bitter pit. J. Hort. Sci. 52:19-28.

Creasy, L.L. 1968. The role of low temperature in anthocyanin synthesis in 'McIntosh' apples. Proc. Amer. Soc. Hort. Sci. 93:716-724.

Creelman, R.A. and J.E. Mullet. 1997. Biosynthesis and action of jasmonates in plants. Annu. Rev. Plant Physiol. Plant Mol. Biol. 48:355-381.

DeLong, W.A. 1936. Variations in the chief ash constituents of apples affected with blotchy core. Plant Physiol. 11:453-456.

Fan, X., J.P. Mattheis, and J.K. Fellman. 1998. A role for jasmonates in climacteric fruit ripening. Planta 204:444-449.

Fan, X., J.P. Mattheis, J.K. Fellman, and M.E. Patterson. 1997. Effect of methyl jasmonate on ethylene and volatile production by 'Summerred' apples depends on fruit developmental stage. J. Agr. Food Chem. 45:208-211.

Feys, B.J.F., C.E. Benedetti, C.N. Penfold, and J.G. Turner. 1994. Arabidopsis mutants selected for resistance to the phytotoxin coronatine are male sterile, insensitive to methyl jasmonate, and resistant to a bacterial pathogen. Plant Cell 6:751-759.

Franceschi, V.R. and H.D. Grimes. 1991. Induction of soybean vegetative storage proteins and anthocyanins by low-level atmospheric methyl jasmonate. Proc. Natl. Acad. Sci. USA. 88:6745-6749.

Greene, D.W. 1986. Effect of paclobutrazol and analogs on growth, yield, fruit quality, and storage potential of 'Delicious' apples. J. Amer. Soc. Hort. Sci. 111:328-332.

Irving, H.R., G. Dyson, R. McConchie, R.W. Parish, and C.A. Gehring. 1999. Effects of exogenously applied jasmonates on growth and intracellular pH in maize coleoptile segments. J. Plant Growth Regulat. 18:93-100.

Kondo, S. and K. Fukuda. 2001. Changes of jasmonates in grape berries and their possible roles in fruit development. Scientia Hort. 91:275-288.

Kondo, S., T. Naoko, Y. Niimi, and H. Seto. 2001. Interactions between jasmonates and abscisic acid in apple fruit, and stimulative effect of jasmonates on anthocyanin accumulation. J. Jpn. Soc. Hort. Sci. 70:546-552.

Looney, N.E. 1979. Some effects of gibberellins $A_{4+7}$ plus benzyladenine on fruit weight, shape, quality, Ca content, and storage behaviour of 'Spartan' apple. J. Amer. Soc. Hort. Sci. 104:389-391.

McGuire, R.G. 1992. Reporting of objective color measurements. HortScience 27:1254.

Merzlyak, M.N. and O.G. Chivkunova. 2000. Lightstress-induced pigment changes and evidence for anthocyanin photoprotection in apples. J. Photochem. Photobiol. B: Biol. 55:155-163.

Perez, A.G., C. Sanz, D.G. Richardson, and J.M. Olias. 1993. Methyl jasmonate vapor promotes ß-carotene synthesis and chlorophyll degradation in 'Golden Delicious' apple peel. J. Plant Growth. Regulat. 12:163-167.

Perring, M.A. 1984. Lenticel blotch pit, watercore, splitting and cracking in relation to calcium concentration in the apple fruit. J. Sci. Food Agr. 35:1165-1173.

Privé, J., D.C. Elving, and J.T.A. Proctor. 1989. Paclobutrazol, gibberellin, and cytokinin effects on growth, development, and histology of apple pedicels and fruits. J. Amer. Soc. Hort. Sci. 114:273-278.

Reay, P.F. 1999. The role of low temperatures in the development of the red blush on apple fruit ('Granny Smith'). Scientia Hort. 79:113-119.

Ritenour, M.A., S. Kochhar, L.E. Schrader, T. Hsu, and M.S.B. Ku. 2001. Characterization of heat shock protein expression in apple peel under field and laboratory conditions. J. Amer. Soc. Hort. Sci. 126:564-570.

Rudell, D.R., J.P. Mattheis, X., Fan, and J.K. Fellman. 2002. Methyljasmonate enhances anthocyanin accumulation and modifies production of phenolics and pigments in 'Fuji' apple fruit. J. Amer. Soc. Hort. Sci. 127:435-441.

Saniewski, M., A. Miszczak, L. Kawa-Miszczak, E. Wegrzynowicz-Lesiak, K. Miyamoto, and J. Ueda. 1998a. Effects of methyl jasmonate on anthocyanin accumulation, ethylene production, and $\mathrm{CO}_{2}$ evolution in uncooled and cooled tulip bulbs. J. Plant Growth Regulat. 17:33-37.

Saniewski, M., K. Miyamoto, and J. Ueda. 1998b. Methyl jasmonate induces gums and stimulates anthocyanin accumulation in peach shoots. J. Plant Growth Regulat. 17:121-124.

Saure, M.C. 1996. Reassessment of the role of calcium in development of bitter pit in apple. Austral. J. Plant Physiol. 23:237-243.

Sun, B.H. and F.J. Francis. 1967. Apple anthocyanins: Identification of cyanidin-7-arabinoside. J. Food Sci. 32:647-649.

Uota, M. 1952. Temperature studies on the development of anthocyanin in 'McIntosh' apples. Proc. Amer. Soc. Hort. Sci. 59:231-237.

Workman, M. 1963. Color and pigment changes in 'Golden Delicious' and ‘Grimes Golden' apples. Proc. Amer. Soc. Hort. Sci. 83:149-161. 